04;07

\title{
Влияние уровня легирования исходных монокристаллов кремния на параметры структуры пористого кремния, полученного методом электрохимического травления
}

\author{
(C) А.Г. Зегря ${ }^{1}$, В.В. Соколов ${ }^{1}$, Г.Г. Зегря ${ }^{1}$, Ю.В. Ганин ${ }^{2}$, Ю.М. Михайлов ${ }^{2}$ \\ ${ }^{1}$ Физико-технический институт им. А.Ф. Иофрфе РАН, Санкт-Петербург, Россия \\ ${ }^{2}$ Институт проблем химической ффизики РАН, Черноголовка, Московская обл., Россия \\ E-mail: zegrya@bk.ru
}

Поступило в Редакцию 18 марта 2019г.

В окончательной редакции 2 июля 2019 г.

Принято к публикации 3 июля 2019 г.

Выявлено воздействие относительно небольших изменений концентрации свободных носителей заряда в сильнолегированном монокристаллическом кремнии p-типа проводимости на структурные параметры пористых слоев, образующихся в результате его анодного травления. Выраженное влияние дырочной концентрации на исследуемые параметры структуры пористого кремния объясняется исходя из представлений об электрохимическом порообразовании в кристаллах кремния как о самоорганизующемся кооперативном процессе, сопровождающемся инжекцией электронов из области химической реакции на фронте продвижения пор.

Ключевые слова: пористый кремний, электрохимическое травление, уровень легирования, пористость, удельная площадь поверхности.

DOI: 10.21883/PJTF.2019.21.48463.17791

Пористый кремний впервые был получен в 1956 г. в ходе изучения процессов электрохимической полировки поверхности кристаллов кремния во фторсодержащих электролитах. Однако активное исследование структуры, свойств и процессов образования пористого кремния началось только в 90-е годы после открытия его люминесцентных свойств [1]. Впоследствии были обнаружены и другие необычные свойства наноструктурированного пористого кремния, такие как фотосенсибилизация перехода в синглетное состояние адсорбированных на нем молекул кислорода [2] и способность к взрывному превращению в контакте с окислителями, заполняющими пространство пор [3]. Биосовместимость и способность к биодеградации, сочетающиеся с гигантской удельной поверхностью скелетных кристаллов пористого кремния и высокой сорбционной активностью, делают пористый кремний перспективным контейнерным материалом для создания лекарственных препаратов пролонгированного действия [4]. В настоящее время пористый кремний находит применение в самых широких областях современной техники: от фотонных кристаллов до химических сенсоров и литиевых аккумуляторов $[5,6]$.

Очевидно, что наблюдаемое разнообразие физикохимических свойств пористого кремния обусловлено главным образом широким диапазоном изменений его структурных параметров в зависимости от условий образования. Поэтому при получении пористого материала из исходных монокристаллов особенно важно представлять факторы, оказывающие наибольшее воздействие на формирование пористой структуры.
Целью настоящей работы является установление степени влияния вариаций уровня легирования исходного кристаллического кремния на структурные характеристики пористого продукта, такие как удельная поверхность, пористость, кажущаяся плотность, средний диаметр пор и распределение их по размерам, а также определение зависимостей этих параметров от скорости протекания электрохимического процесса (рис. 1-3).

Исходным материалом для получения пористого кремния в настоящей работе служили две партии пластин монокристаллического кремния с высоким, но различающимся уровнем легирования бором. Уровень легирования исходных пластин диаметром $150 \mathrm{~mm}$ и толщиной $640 \mu \mathrm{m}$ определялся по величине их удельного сопротивления. Измерения проводились наиболее простым и удобным четырехзондовым методом, применимым для определения удельного сопротивления монокристаллов в широком диапазоне его значений (от $10^{-5}$ до $10^{5} \Omega \cdot \mathrm{cm}$ ). Полученные значения составили $0.0020-0.0021$ и $0.0044-0.0045 \Omega \cdot \mathrm{cm}$ соответственно.

Пересчитанные на величину концентрации свободных носителей заряда средние значения удельного сопротивления дают $2.4 \cdot 10^{19} \mathrm{~cm}^{-3}$ для первой группы образцов и $1.1 \cdot 10^{19} \mathrm{~cm}^{-3}$ для второй, что близко к порогу вырождения для кремния с дырочной проводимостью.

Слои пористого кремния были получены путем двустороннего электрохимического травления в гальваностатическом режиме пластин монокристаллического кремния с ориентацией поверхности $\langle 100\rangle$. В качестве электролита использовалась смесь равных объемов плавиковой кислоты $(48 \% \mathrm{HF})$ и этилового спирта. 


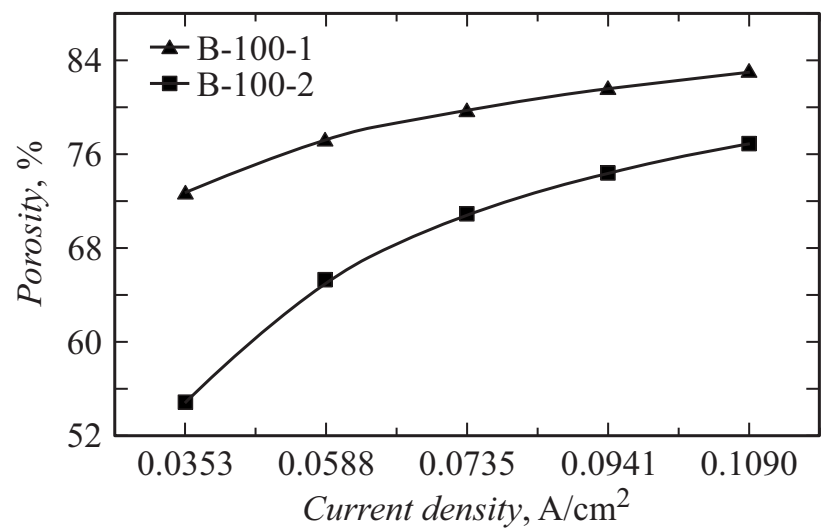

Рис. 1. Зависимости степени пористости структуры пористого кремния, полученного из сильнолегированных кристаллов кремния $p$-типа с разными уровнями легирования (образцы B-100-1 $(\rho=0.0021 \Omega \cdot \mathrm{cm})$ и В-100-2 $(\rho=0.0045 \Omega \cdot \mathrm{cm}))$, от величины плотности анодного тока.

На пластинах каждой группы были получены пористые слои при величинах плотностей анодного тока $(j)$ : $35.3,58.8,73.5,94.1$ и $109 \mathrm{~mA} / \mathrm{cm}^{2}$.

Электрохимическое травление пластин высоколегированного кремния $p$-типа проводимости позволяет получать однородные механически стабильные слои мезопористого материала толщиной до $\sim 250 \mu \mathrm{m}$ и пористостью до $\sim 83 \%$. Структура таких слоев формируется системой ветвящихся пор, распространяющихся преимущественно вдоль кристаллографических направлений $\langle 100\rangle$.

После завершения процесса электрохимического порообразования поверхность стенок сформировавшихся пор покрывается сплошным слоем хемосорбированных атомов водорода, замыкающих вакантные связи атомов кремния. Гидрирование изначально фторированной в ходе анодного травления кремния поверхности происходит за счет удаления внешнего слоя атомов $\mathrm{Si}$ при контакте с HF-содержащим электролитом согласно схеме

$$
=\mathrm{Si}=\mathrm{Si}=\mathrm{F}_{2}+2 \mathrm{~F}^{-}+2 \mathrm{H}^{+} \rightarrow=\mathrm{Si}=\mathrm{H}_{2}+\mathrm{SiF}_{4} .
$$

Исследование структурных параметров образцов наноструктурированного пористого кремния проводилось методом адсорбционно-структурного анализа [6] на анализаторе ASAP 2020 (Micromeritics) по изотермам адсорбции и десорбции азота при $77 \mathrm{~K}$. Этот метод позволяет определять структурные параметры различных пористых материалов с наноразмерными структурными элементами.

Навеска наноструктурированного пористого кремния помещалась в измерительную колбу и подвергалась дегазации. После дегазации колба с образцом перемещалась на измерительный блок и в автоматическом режиме проводилось измерение изотерм адсорбции и десорбции азота. Встроенное программное обеспечение позволяет провести анализ полученных данных и определить численные значения следующих структурных характеристик: средний диаметр пор $\left(d_{S}\right)$, удельная площадь поверхности $\left(S_{S}\right)$, суммарный удельный объем пор $\left(V_{\Sigma}\right)$. Кажущаяся плотность $\left(\rho_{a}\right)$ рассчитывается по формуле

$$
\rho_{a}=\frac{1}{\left(1 / \rho_{p}\right)+V_{\Sigma}}
$$

где $\rho_{p}=2.425 \mathrm{~g} / \mathrm{cm}^{3}$ - пикнометрическая плотность пористого кремния по гелию, измеренная на газовом пикнометре Ultrapycnometer 1000. Для определения пикнометрической плотности навеска пористого кремния помещалась в измерительную ячейку прибора. В импульсном режиме проводилось 20 циклов предварительной дегазации. По результатам десяти последовательных измерений прибор выдает усредненное значение пикнометрической плотности $\rho_{p}$ кремниевого скелета в пористом материале.

Пористость $(P)$ рассчитывается как

$$
P=\left(1-\frac{\rho_{a}}{\rho_{p}}\right) \cdot 100 \% .
$$

В соответствии с описанной методикой были определены структурные параметры каждого из полученных образцов наноструктурированного пористого кремния.

Несмотря на относительно небольшую для близкого к вырождению полупроводника (двукратную) разницу
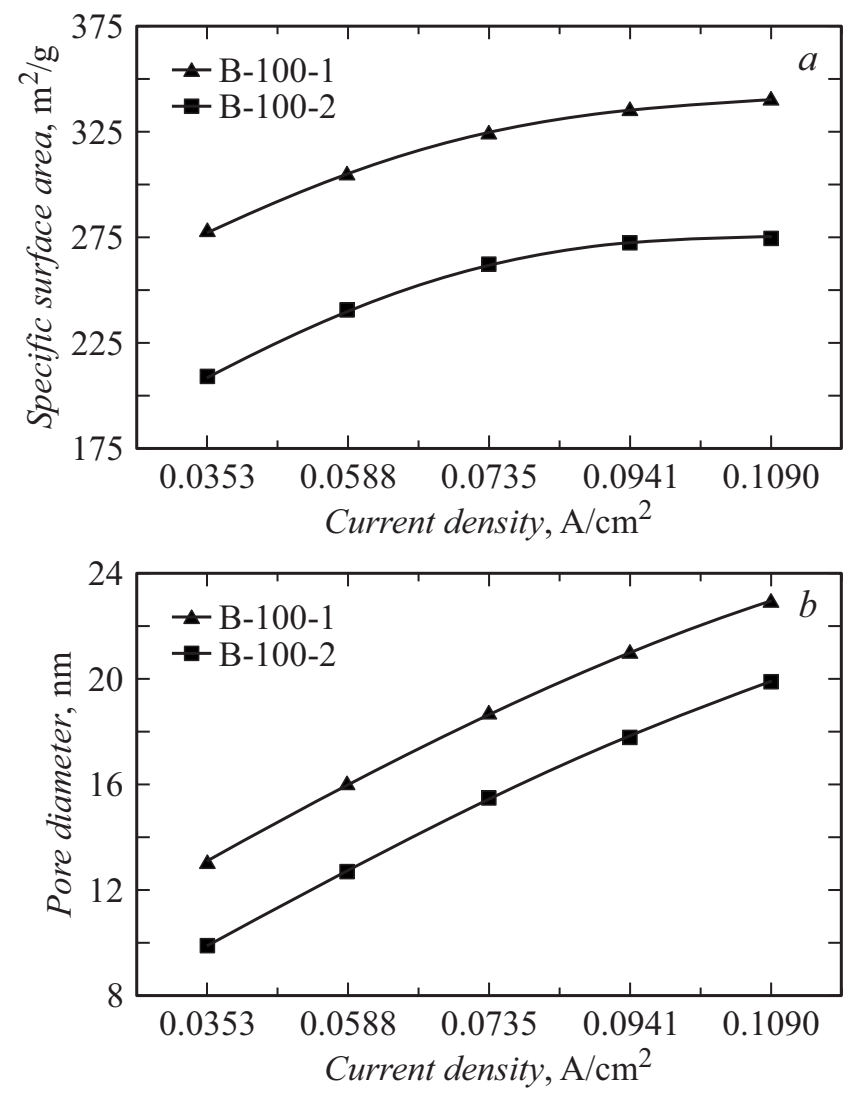

Рис. 2. Зависимости удельной площади поверхности пористого кремния $(a)$ и среднего диаметра пор $(b)$ от плотности анодного тока. 
в уровне легирования исходных пластин, значения кажущейся плотности, пористости, суммарной площади поверхности, среднего диаметра и суммарного объема пор в полученных из них слоях пористого кремния существенно различаются. Снижение уровня акцепторного легирования ведет к заметному уменьшению значений удельной площади поверхности (в 1.3-1.4 раза), среднего диаметра пор (в 1.1-1.3 раза), суммарного объема пор (в 1.5-1.7 раза) и пористости получаемых образцов (в 1.1-1.2 раза), тогда как значения кажущейся плотности возрастают (в 1.35-1.45 раза) (рис. $1-3$ ).

Согласно развиваемым нами представлениям, в основе самоорганизующихся анодных процессов, приводящих к появлению и прорастанию пор в полупроводниковых кристаллах, лежат кооперативные химические реакции нуклеофильного замещения между компактными группами хемосорбированных анионов, образующих плотные адсорбционные покрытия, и координационно насыщенными атомами приповерхностного слоя решетки. Эти реакции инициируются при достижении определенной для данной комбинации составов полупроводника и хемосорбированных анионов величины падения потенциала в слое Гельмгольца. Разрыв химических связей в кристалле при релаксации переходных комплексов и образовании первичных полимерных продуктов кооперативной реакции сопровождается импульсным высвобождением электронов в зону проводимости, которые и обеспечивают протекание анодного тока [7]. Остающиеся вакантными орбитали оборванных связей на вновь образовавшейся поверхности кристалла и отщепившихся от него продуктах заполняются адсорбирующимися из раствора анионами, что завершает элементарный цикл продвижения канала поры в глубь кристалла [8].

В полупроводнике $p$-типа проводимости инжектируемые электроны должны рекомбинировать с дырками в непосредственной близости от фронта продвижения химической реакции. Следствием энерговыделения, сопровождающего рекомбинационные процессы, становится разогрев прифронтальной области кристалла [9]. В непрямозонных полупроводниках, каким является кремний, этот эффект должен проявляться в наибольшей степени. С повышением локальной температуры в зоне реакции возрастают амплитуды и частоты тепловых флуктуаций, способствующих преодолению активационных барьеров для запуска кооперативных многочастичных процессов нуклеофильной атаки адсорбированных анионов на атомы кристалла на дне каждой из прорастающих пор [7]. Это в свою очередь создает условия для пространственного расширения локальных областей протекания кооперативной реакции и увеличения частоты повторения ее дискретных актов при данной фиксированной величине падения потенциала в адсорбционном слое. Как следствие, должно происходить увеличение размеров пор с увеличением глубины их проникновения в кристалл, что и наблюдается на практике. Поскольку с повышением концентрации свободных дырок уменьшается длина диффузии неравновесных электронов и
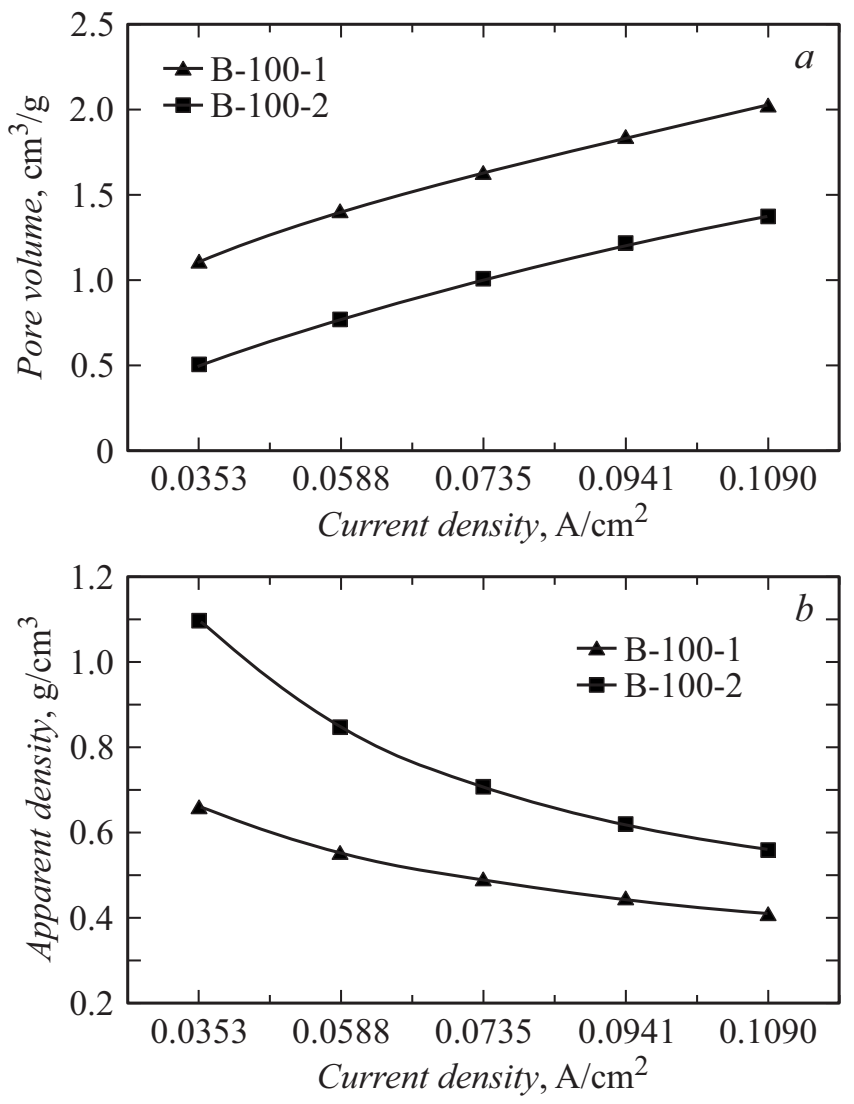

Рис. 3. Зависимости суммарного объема пор $(a)$ и кажущейся плотности пористого кремния $(b)$ от плотности анодного тока.

сужается область их эффективной рекомбинации, плотность выделяемой энергии на фронте порообразования и соответственно локальная температура должны возрастать [7]. В кристаллах p-типа проводимости глубина проникновения инжектируемых электронов определяется их диффузионной длиной

$$
L_{D}=\left(D_{n} \tau_{l}\right)^{1 / 2}
$$

где $D_{n}-$ коэффициент диффузии для электронов, составляющий в кремнии при $300 \mathrm{~K}$ величину $D_{n}=36 \mathrm{~cm}^{2} / \mathrm{s}[10], \tau_{l}$ - время жизни электронов. Это время определяется двумя каналами рекомбинации: излучательной и безызлучательной (оже) рекомбинацией

$$
\frac{1}{\tau_{l}}=\frac{1}{\tau_{p h}}+\frac{1}{\tau_{A}}
$$

где $\tau_{p h}-$ время излучательной рекомбинации, $\tau_{A}-$ время оже-рекомбинации. Подставляя явное выражение для $\tau_{l}$ в выражение $(3)$, получим

$$
L_{D}=\left[\frac{D_{n}}{\left(B+C^{C} n+C^{H} p\right) p}\right]^{1 / 2},
$$

где $B-$ коэффициент излучательной рекомбинации, $C^{C}-$ коэффициент оже-рекомбинации для 
CHCC-процесса (процесса с возбуждением электрона), $C^{H}-$ коэффициент оже-рекомбинации для CHHS-процесса (процесса с возбуждением дырки) [11]. С этим, очевидно, связано выявленное в настоящей работе значительное увеличение размеров пор при повышении дырочной концентрации в сильнолегированном кремнии (рис. 2,b). В более слаболегированных невырожденных кристаллах кремния аналогичные эффекты также должны присутствовать, однако вследствие существенного снижения потока тепла к фронту порообразования зависимости структурных параметров от концентрации дырок должны проявляться намного слабее, что и подтверждается известными экспериментальными данными [9].

В работе показано, что относительно небольшие вариации концентрации свободных носителей заряда в сильнолегированных вырожденных кристаллах кремния $p$-типа проводимости способны оказывать существенное влияние на структурные параметры пористого кремния, образующегося из них в процессе анодного травления. Предложена интерпретация наблюдаемых корреляций в рамках модели, описывающей электрохимическое порообразование в алмазоподобных полупроводниковых кристаллах как самоорганизующуюся систему локальных кооперативных химических процессов, протекание которых сопровождается импульсной инжекцией электронов в зону проводимости полупроводника.

\section{Финансирование работы}

Работа выполнена при поддержке Российского фонда фундаментальных исследований (грант № 16-29-0108 офи_м).

\section{Конфликт интересов}

Авторы заявляют, что у них нет конфликта интересов.

\section{Список литературы}

[1] Canham L.T. // Appl. Phys. Lett. 1990. V. 57. P. 1046-1048.

[2] Kovalev D., Gross E., Kunzner N., Koch F., Timoshenko V.Yu., Fujii M. // Phys. Rev. Lett. 2002. V. 89. P. 137401.

[3] Kovalev D., Timoshenko V.Yu., Künzner N., Gross E., Koch F. // Phys. Rev. Lett. 2001. V. 87. P. 068301.

[4] Ксенобонтова О.И., Васин А.В., Егоров В.В., Бобыль А.В., Солдатенков Ф.Ю., Теруков Е.И., Улин В.П., Улин Н.В., Киселев О.И. // ЖТФ. 2014. Т. 81. В. 1. С. 67-78.

[5] Porous silicon: from formation to application / Ed. G. Korotcenkov. London: CRC Press, 2016.

[6] Кравчик А.Е., Кукушкина Ю.А., Соколов В.В., Терещенко Г.Ф., Устинов Е.А. // ЖПХ. 2008. Т. 81. В. 10. С. 1605 1612.

[7] Улин В.П., Улин Н.В., Солдатенков Ф.Ю. // ФТП. 2017. T. 51. B. 4. C. 481-496.
[8] Астрова Е.В., Федулова Г.В., Смирнова И.А., Ременюк А.Д., Кулова Т.Л., Скундин А.М. // Письма в ЖТФ. 2011. T. 37. В. 15. C. $87-94$.

[9] Улин В.П., Конников С.Г. // ФТП. 2007. Т. 41. В. 7. С. $867-$ 877.

[10] New semiconductor materials: characteristics and properties. Databases, archives and catalogs. http://www.matprop.ru

[11] Lehmann V., Stengl R., Luigart A. // Mater. Sci. Eng. B. 2000. V. 69-70. P. 11-22. 